\title{
Introduction to Managing Platforms and Ecosystems Minitrack
}

\author{
Kaisa Still \\ VTT Technical Research \\ Centre of Finland Ltd \\ kaisa.still@vtt.fi
}

\author{
Jukka Huhtamäki \\ Tampere University of Technology \\ jukka.huhtamaki@tut.fi
}

\author{
Rahul Basole \\ Georgia Institute of Technology \\ basole@gatech.edu
}

The minitrack seeks contributions that draw from diverse theoretical backgrounds such as engineering, computer science, decision science, system science, organizational design, and behavioral economics to continue the scholarly exploration of concepts, theories, models, and tools for managing platforms and ecosystems. We are open to a wide set of methodological approaches including empirical research, case-based research, field studies, and behavioral decision making experiments. We encourage collaboration between academia and industry and welcome diverse submissions by both industry and geography.

Conceptually, the mindsets, organizational constructs, and the technological systems of multisided markets, platforms, and ecosystems require a reframed perspective on strategic management that goes beyond extant literature on strategic and industrial innovation. While principles and tactics for managing platforms and ecosystems are emerging, more crossdisciplinary research, thought leadership and experience sharing are needed.
Topics of interest include, but not limited to:

- Theories, models, and empirical studies of platforms and ecosystems

- Genesis, dynamics, and evolution of platforms and ecosystems, including the role of boundary resources

- Platforms and ecosystems for firm innovation

- Platform and ecosystem business models

- Technological and competitive disruption in ecosystems

- Analytics, visualization, and decision support for platform and ecosystems

- Best practices in platform and ecosystem management

- Orchestration strategies for platforms and ecosystem

- Case studies of successes, failures, and unintended consequences of platforms and ecosystems 